\title{
Microbial conversion of progesterone with Aspergillus sp.
}

\author{
Guangqiu Zhang ${ }^{\mathrm{a}}$, Shujuan $\mathrm{Li}^{\mathrm{b}}$, Haiying Yang ${ }^{\mathrm{c}}$ *
}

\author{
Engineering Research Center of Biopolymer Functional Materials of Yunnan, Yunnan Minzu \\ University, Kunming 650031, P.R.China \\ azhanggq790129@126.com, ${ }^{\mathrm{b}} 1520201595 @ q q . c o m$, \\ cyanghy200401@126.com (corresponding author)
}

\begin{abstract}
Keywords: Progesterone, metabolites, Bioconversion, Aspergillus sp.
\end{abstract}
\begin{abstract}
The conversion of progesterone (1) by Aspergillus sp. was studied. The major metabolites

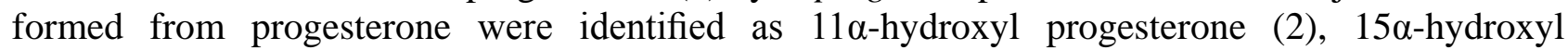

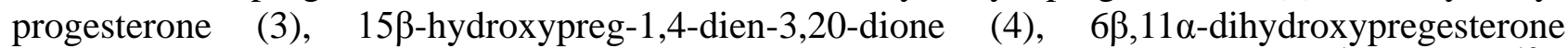
(5).Conversion products were characterized by spectroscopic methods including ${ }^{1} \mathrm{H} N M R,{ }^{13} \mathrm{C}$ NMR and MS.
\end{abstract}

\section{Introduction}

Microbial conversion of steroids provide an important method of obtaining new steroid derivatives of potential pharmaceutical activity, which additionally fulfills green chemistry principles[1-2]. The major advantage of biological catalysts is their capability to catalyze novel reactions with regio- and stereo-selectivity[3]. Since $11 \alpha$ - hydroxylation of progesterone by Rhizopus arrhizus was patented in 1952[4]. A wide variety of microorganisms have been investigated and have been successfully applied to transform a wide range of steroids to produce functionalized compounds with therapeutic use and commercial value[5-7].

The Aspergillus genus is an important source of fungal pathogen which can cause severe seed yield loss in soybeans and other crops[8]. However, strains of Aspergillus genus had never used in the biotransformation of steroids. During our screening program for isolation of microorganism from Paris polyphylla Smith var. Yunnanenis capable of transforming progesterone, a strain of Aspergillus sp. was isolated from rhizome of Paris polyphylla Smith var. yunnanenis and applied for converting progesterone hydroxylation in different position.

\section{Materials and methods}

\section{Chemicals}

Progesterone (1) was purchased from Yancheng Xinyi Pharm\&Che Co., Ltd, Yancheng, China. It was assayed at $>99 \%$ purity by HPLC (PDA as detector).

\section{Microorganism}

The fungal strain Aspergillus sp. was isolated from Paris polyphylla Smith var. yunnanenis collected from Baoshan, Yunnan province, PRC. The strain of Aspergillus sp. was grown at 28C and stored at4C on agar slopes composed of Glucose (30.0 g), potato (100.0 g),agar (20 g) mixed into distilled $\mathrm{H}_{2} \mathrm{O}(1 \mathrm{~L})$.

\section{Culture conditions and transformation}

Aspergillus sp. broth media were transferred into $250 \mathrm{~mL}$ conical flask (100 mL each). It was prepared with medium (1 L): Glucose (30.0 g), $\mathrm{K}_{2} \mathrm{HPO}_{4}(1 \mathrm{~g}), \mathrm{MgSO}_{4} \bullet 7 \mathrm{H}_{2} \mathrm{O}(0.5 \mathrm{~g}), \mathrm{KCl}(0.5 \mathrm{~g})$, $\mathrm{FeSO}_{4}(0.01 \mathrm{~g})$, and $\mathrm{pH}$ was maintained at 5.8. $10 \mathrm{~g}$ progesterone and $4 \mathrm{~g}$ Tween80 dissolved in acetone were mixed into broth media $(10 \mathrm{~L})$.Seed flasks without progesterone were prepared from three-day old slants and allowed for one day on a shaker at 28C. The remaining flasks within progesterone were inoculated from the seed flasks and placed on a rotatory shaker (180 rpm) at 28C for fermentation for $96 \mathrm{~h}$. 


\section{Analysis}

Melting points were determined by a Buchi 535 melting-point apparatus. Optical rotations were measured on a Jasco P-2000 digital polarimeter. EI-MS was recorded on an Agilent 5973N. ${ }^{1} \mathrm{H}$ NMR and ${ }^{13} \mathrm{C}$ NMR spectra were performed on Bruker 400 spectrometers with TMS as internal standard. Column chromatography was performed on silica gel (200-300 mesh; Qingdao). Thin layer chromatography (TLC) analysis was carried out on precoated plates with $0.20-0.25 \mathrm{~mm}$ thick silica gel GF254 (Qingdao) with detection by heating silica gel plates sprayed with $10 \% \mathrm{H}_{2} \mathrm{SO}_{4}$ in EtOH.

\section{Isolation of transformed products}

The mycelium was filtered from the fermentation broth and extracted three times with ethanol, while the broth was extracted three times with EtOAc. That was evaporated under reduced pressure and brown crude (10.53 g) was obtained. Then the crude was subject to silica gel CC to afford Compound 2 (345 mg), 3 (123 mg), 4 (13 mg), 5 (18 mg) on elution with petroleum ether/EtOAc (9:1-1:9), Chemical structures of the products were determined by means of spectral data and mentioned in respective order.

\section{Results and discussion}

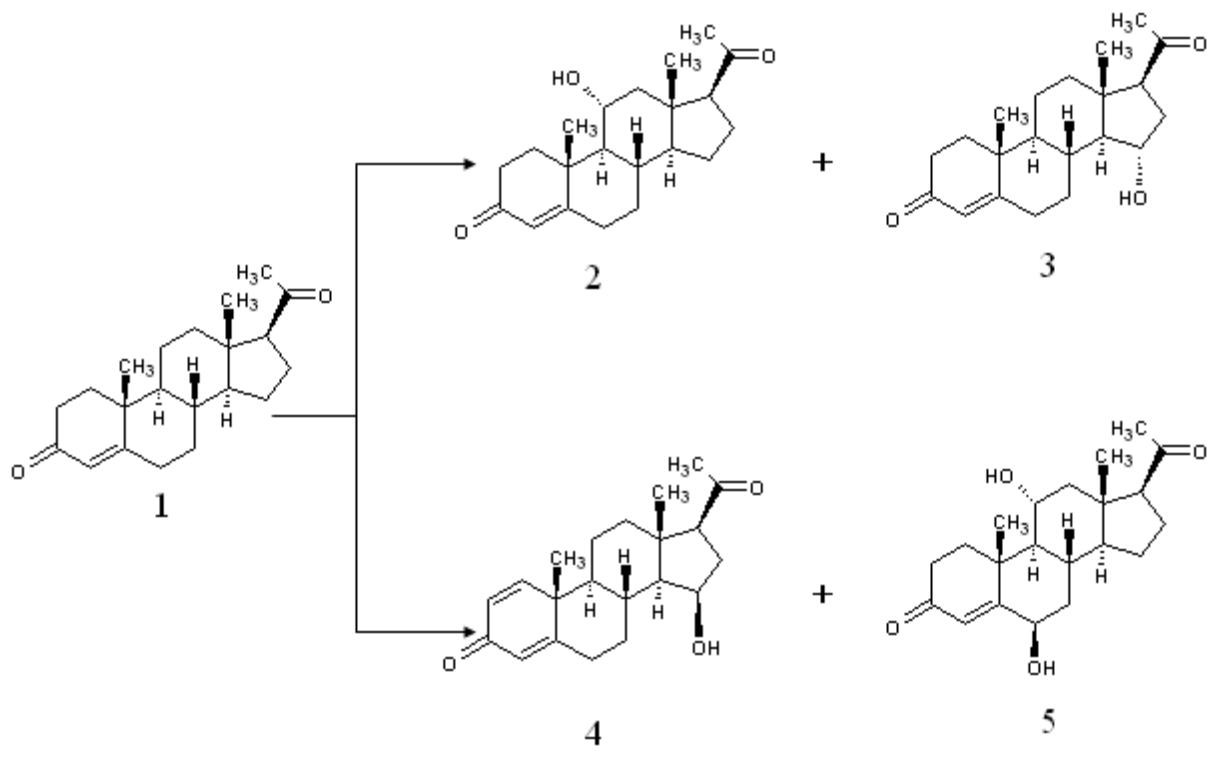

Fig. 1. The structures of Progesterone (1) and the biotransformed products $11 \alpha$-hydroxyl progesterone (2), 15 $\alpha$ hydroxyl progesterone (3), 15 $\beta$-hydroxypreg-1,4-dien-3,20-dione (4), 6 $\beta, 11 \alpha$-dihydroxypregesterone (5).

A.versicolor converted progesterone into the compound 2, 3, 4 and 5 (Fig. 1). All of them are more polar than the substrate itself. ${ }^{13} \mathrm{CNMR}$ data of the substrate as well as the conversion products are listed in Table 1. The analytical data of compound 2, 3, 4 and 5 are mentioned in respective order.

$11 \alpha$-hydroxyprogesterone (2) Crystallized from methanol; m.p.: 155-157 ${ }^{\circ} \mathrm{C} .{ }^{1} \mathrm{H}$ NMR (CDC

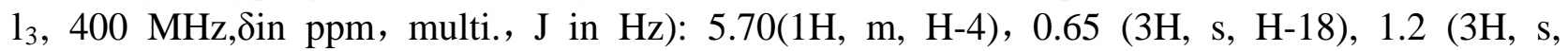
$\mathrm{H}-19), 4.99$ (1H, m, H-11). ESI-MS: m/z $354.2[\mathrm{M}+\mathrm{Na}]^{+} ; \mathrm{m} / \mathrm{z} 369.2[\mathrm{M}+\mathrm{K}]^{+}$. Mass spectru $\mathrm{m}$ indicated a molecular of composition $\mathrm{C}_{21} \mathrm{H}_{30} \mathrm{O}_{3}$. It unequivocally confirms the structure $\mathrm{o}$ f $11 \alpha$-hydroxyprogesterone[9,10].

15a-hydroxyl progesterone (3) Crystallized from methanol; m.p.: 229-231C (methanol). ${ }^{1} \mathrm{H}$ NMR $\left(\mathrm{CDCl}_{3}, 400 \mathrm{MHz}, \delta\right.$ in ppm, multi., J in $\left.\mathrm{Hz}\right): 5.64(1 \mathrm{H}, \mathrm{m}, \mathrm{H}-4), 4.10(1 \mathrm{H}, \mathrm{m}, \mathrm{H}-$

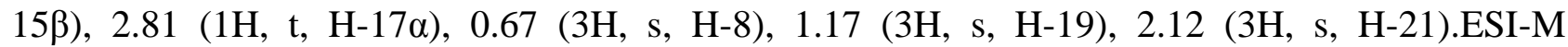
$\mathrm{S}: \mathrm{m} / \mathrm{z}: 353[\mathrm{M}+\mathrm{Na}]^{+}$. Mass spectrum indicated a molecular of composition $\mathrm{C}_{21} \mathrm{H}_{30} \mathrm{O}_{3}$. It is

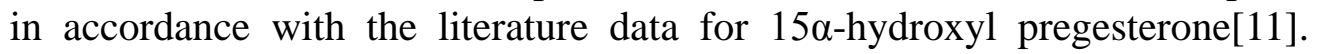

15ß-hydroxypreg-1,4-dien-3,20-dione (4) Crystallized from methanol; m.p.: 229-234 ${ }^{\circ} \mathrm{C} .{ }^{1} \mathrm{H}$ NMR $\left(\mathrm{CDCl}_{3}, 400 \mathrm{MHz}, \delta\right.$ in ppm, multi., J in $\left.\mathrm{Hz}\right): 6.09(1 \mathrm{H}, \mathrm{s}, \mathrm{H}-4), 7.06(1 \mathrm{H}, \mathrm{d}, \mathrm{H}-1)$, 
6.20 (1H, dd, H-2) ,2.42 (1H, m, H-17), 0.88 (3H, s,H-18), 1.20 (3H, s, H-19), 2.08 (3H, s, H-21).ESI-MS: $\mathrm{m} / \mathrm{z} 351[\mathrm{M}+\mathrm{Na}]^{+}$. Mass spectrum indicated a molecular of composition $\mathrm{C}$ ${ }_{21} \mathrm{H}_{28} \mathrm{O}_{3}$.It is in accordance with the literature data for $11 \alpha$-hydroxypreg-1,4-dien-3,20-dione[1 2].

6 $\beta, 11 \alpha$-dihydroxypregesterone (5) Crystallized from methanol;m.p.: 245-248 ${ }^{\circ} \mathrm{C} .{ }^{1} \mathrm{H}$ NMR $\left(\mathrm{CDCl}_{3}, 400 \mathrm{MHz}, \delta\right.$ in ppm, multi., $\mathrm{J}$ in $\left.\mathrm{Hz}\right): 5.78(\mathrm{~s}, 1 \mathrm{H}, \mathrm{H}-4$ ), $2.68(\mathrm{t}, 1 \mathrm{H}, \mathrm{H}-17), 0.7$ 3 (s, 3H, H-18), 1.49 (s, 3H, H-19), 2.14 (s, 3H, H-21),4.34 (m, 1H, H-6), 4.09 (m, 1H,H11).ESI-MS: $\mathrm{m} / \mathrm{z} 369[\mathrm{M}+\mathrm{Na}]^{+}$. Mass spectrum indicated a molecular of composition $\mathrm{C}_{21} \mathrm{H}_{30}$ $\mathrm{O}_{4}$. It is in accordance with the literature data for 6 $\beta, 11 \alpha$-dihydroxypregesterone[13].

Table.1. ${ }^{13} \mathrm{C}$ NMR signals of the substrate and metabolites $\left(\delta\right.$ in ppm downfield from TMS, in $\left.\mathrm{CDCl}_{3}\right)$

\begin{tabular}{llllll}
\hline $\mathrm{C}$ & 1 & 2 & 3 & 4 & 5 \\
\hline 1 & 35.7 & 37.6 & 35.8 & 156.8 & 37.5 \\
2 & 34.0 & 34.3 & 34.1 & 127.1 & 34.1 \\
3 & 199.4 & 200.3 & 199.6 & 187.0 & 202.7 \\
4 & 123.9 & 124.7 & 124.0 & 123.4 & 126.0 \\
5 & 170.9 & 170.9 & 170.8 & 170.6 & 170.5 \\
6 & 32.8 & 33.7 & 32.8 & 32.6 & 72.1 \\
7 & 31.9 & 31.6 & 32.1 & 32.5 & 38.6 \\
8 & 35.6 & 35.1 & 35.3 & 31.6 & 28.2 \\
9 & 53.7 & 59.1 & 53.8 & 52.5 & 58.4 \\
10 & 38.7 & 40.1 & 38.7 & 43.8 & 39.2 \\
11 & 21.0 & 69.0 & 21.0 & 22.7 & 68.0 \\
12 & 38.5 & 50.6 & 38.9 & 39.9 & 49.4 \\
13 & 43.9 & 44.26 & 44.7 & 43.9 & 44.1 \\
14 & 56.0 & 55.5 & 62.9 & 59.7 & 55.1 \\
15 & 24.4 & 24.4 & 73.5 & 69.6 & 23.9 \\
16 & 22.8 & 23.1 & 35.4 & 35.7 & 22.7 \\
17 & 63.5 & 63.2 & 61.0 & 63.5 & 63.1 \\
18 & 13.3 & 14.6 & 14.8 & 15.7 & 14.1 \\
19 & 17.4 & 18.4 & 17.6 & 18.4 & 19.5 \\
20 & 209.3 & 208.9 & 208.4 & 209.3 & 210.6 \\
21 & 31.5 & 31.5 & 31.7 & 31.2 & 31.0 \\
\hline
\end{tabular}

\section{Conclusion}

The conversion products of progesterone with Aspergillus sp. including $11 \alpha$-hydroxyl progesterone (2), 15 $\alpha$-hydroxyl progesterone (3), 15 $\beta$-hydroxypreg-1,4-dien-3,20-dione (4), $6 \beta, 11 \alpha$-dihydroxypregesterone(5).The hydroxylation positions include $6 \beta, 11 \alpha, 15 \alpha$ and $15 \beta$ as well as a reaction of dehydrogenation between $\mathrm{C} 1$ and $\mathrm{C} 2$.

\section{Acknowledgement}

This research was supported financially by Open Fund of the Key Laboratory of Chemistry in Ethnic Medicinal Resources (Yunnan Minzu University), State Ethnic Affairs Commission \& Ministry of Education (MZY1401) and the Innovative Experiment Items of Students of Yunnan Minzu University (2013HXSRT05).

\section{References}

[1] Hu S, Genain G, Azerad R. Steroids Vol. 60 (1995), p. 337

[2] Mahato SB, Garai S. Steroids Vol. 62(1997), p. 332

[3] Uhnakova B, Ludwig R, Peknicova J. Bioresour. Technol. Vol. 102(2011), p. 9409

[4] Murray HC, Peterson DH. U.S Patent. Vol. 2(1952), p. 602

[5] Mahato B, Mazumder I. Phytochemistry Vol. 34 (1989), p. 883

[6] Ahmad S, Garg SK, Johri BN. Biotech Adv. Vol. 10(1992), p. 1 
[7] Sedlaczek L. Crit Rev Biotechnol. Vol. 7(1988), p. 187

[8] Sun S, Kim M Y, Chaisan T. Phytopathol. Vol. 161(2013), p. 131

[9] Smith KE, Latif S, Kirk DN, Steroid Biochem. Vol. 32(1989), p.445

[10] Kirk DN, Miller BW, Latif SA. Journal of Chemical Research-S. Vol. 6 (1989), p. 164

[11] Mara BB, Alexander PS, Ivan C. Steroids Vol. 69 (2004), p. 473

[12] Garai S, Banerjee S, Mahato SB. Journal of Chemical Research, Synopses. Vol. 10 (1995), p. 408

[13] Choudhary MI, Batool I, Shah SA. Chem Pharm Bull (Tokyo). Vol. 11 (2005), p. 1455 